\title{
Reventlowerne paa Sandbjerg.
}

\section{Af Chr. Hanssen.}

I Fjor, Hundredaaret efter Christjan Detlev Frederik Reventlow's Død, hvor der i Pressen er fremkommet saa mange Artikler om ham og hans store Værk, var det ret mærkeligt at lagge Mærke til, at der altid kun har været Tale om to Brødre, Chr. Detlef Frederik R., Christianssæde, Lolland, og Johan Ludvig R., Brahetrolleborg. Den tredie Broder Conrad Georg til Lensgrevskabet ReventlowSandbjerg, Ballegaard, Beuskov m. fl. Godser omtales ikke. Heller ikke omtales han i de almindelige Lexika, hvor man næsten ikke kan finde ham blandt de mange Reventlow'er, der nævnes. Men da han i Virkeligheden var lige saa stor en Bondeven som hans yngre Broder Chr. Ditlev Frederik, saa har jeg ikke kunnet undlade at minde om ham ved disse Linjer.

Af de tre Brødre var Conrad Georg den ældste. Han var født 1749 og opkaldt efter Farfaderen, Conrad Reventlow 1644-1708. Han var Kommandør i Søetaten, men boede ofte, især $i$ de senere Aar, paa Sandbjerg. Her boede han blandt sine Bonder, udtrykte han sig. Han blev bedt med til de store Bryllupper, der holdtes den Gang her paa Egnen. Der fortælles, at Præsten i Sottrup, der var tysksindet, havde faaet den Skik indført ved Bryllupper, at naar den første lille vilde komme for tidlig, saa 
maatte Bruden ikke have Slør paa. Dette var Tilfældet, engang Greven var med til Bryllup. Han blev lynende vred, skældte Præsten ud: "Vil din sorte Hund saaledes tortere mine Bønder! Jeg befaler, hun skal have Slør«. Og hun fik det.

Han døde den 20. April 1815 paa Sandbjerg Slot. Forud havde han bestemt, at han vilde hvile paa Kirkegaarden "blandt sine Bønder" og ikke bisættes i det grevelige Reventlowske Kapel ved Koret paa Dybbøl Kirke, for hvilken Lensgreven er Patron. 1863 rejste Bønderne en Mindesten paa hans Grav. Paa den staar der:

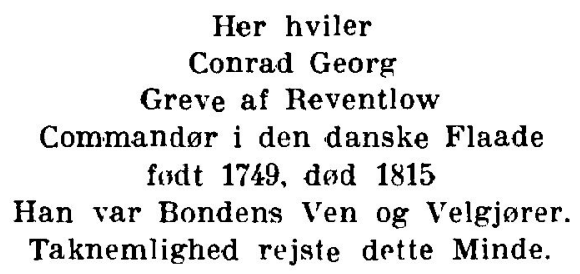

Grunden til, at dette Minde først rejstes 1863, kan maaske være den, at de gode Tider som Stavnsbaandets Løsning, Udskiftningen og Bondens Frigørelse i det hele, nu ved Grev Conrads Dod var aflost af meget daarlige Tider. De store Statsmænd Grev Bernstorf $\mathrm{m}$. fl. var døde, og den lille enevældige Konge var kommet paa den forkerte Side i den store napoleonske Verdenskrig. England tog Flaaden, og Staten gik bankerot, og det tog mange Aar, hele Tyverne igennem, før Landbruget kom lidt paa Fode igen.

At Grev Conrad var Bondens Ven og Velgører, faar man det bedste Indtryk af ved at se en af Kontrakterne, hvorefter Bøndergodset den 1. Maj 1788 blev solgt til ren og frỉ Ejendom, og jeg skal da her meddele Kontrakten mellem Greven og Jorgen Christensen Mattesen i Snogbæk. 
Hans kongelige Majestæet til Danmark og Norge p. p. bestalter Cammerherre og Commandeurkaptein i Søetaten.

J e g, Conrad Georg Greve til Reventlow og Christianssæde Friherre til Brahetrolleborg gjør herved vitterlig, at jeg til min Undersaat den tjenestepligtige Bolsbesidder Jørgen Christensen Mattesen i Snogbæk og hans Arvinger har solgt hans iboende Bol, af 6 Mark Guld, med de dertil hørende Landerier, Skovskifter, Bygninger og Beslag, for saa vidt det sidste tilhører mig, paa de her vedhæftede, til Grund lagte Conditioner, til Arv og Eje, og samtidig givet ham Frihed for al hidtilværende Hovarbejde, saaledes at han fra 1. Maj d. A. af dette Bol aarlig svarer 28 Rigsdaler Contribution, og 12 Rigsdaler Canon, tilsammen altsaa 40 Rigsdaler, deraf $16 \mathrm{Da}$ ler i klingende Mønt. To Trediedele af denne Afgift skal betales til Jul og en Trediedel til Majdag promte. Endvillere betaler Kjøberen af dette Bol en Kjøbeskilling af et Tusinde og et Hundrede Rigsdaler og desforuden for Træerne i Skovskiftet efter Taxationen til Jul dette Aar 136 Rigsdaler.

Naar nu Køberen af Købesummen 1100 Rdl. straks betaler 100 Rdl., og udsteder en Panteobligation til mig og mine Lensefterfølgere paa Resten $=1000 \mathrm{Rdl}$, paa 1ste Prioritet til 4 pCt. p. A. indfort i den ny oprettede Skyld- og Panteprotokol, saa indsatter jeg Køberen Jørgen Christensen Mattesen og hans Arvinger i Henhold til (lenne Kontrakt til Ejer af bemeldte Bol, altsaa og saaledes, at Køberen under Iagttagelse af de vedhæftede Conditioner og promte Betaling af Afgifterne og Købeskilling, kan skalte og valte, pantsætte, sælge Bolet, som med sin anden ovrige Ejendom. Men Køberen maa ikke kræve andre Friheder og Rettigheder end Conditionerne indeholder, saaledes at anlægge et Teglværk paa sine Landerier uden herskabelig Consens. Der gives Køberen som de øvrige Undersaatter den Forsikring, at han, naar den nuværende Kropagt er endt, altsaa til Jul d. Aar, skal være befriet for Krotvang. Ligesaa naar den Sønderborger Stadsmusikant ved Døden eller paa anden Maade 
fratræder, skal Køberen ikke være bunden eller forpligtet til dennes Efterfolger. - Det forstaar sig af sig selv, at da de danske Banksedler og Mønt vil blive sat ud af Curs i Hertugdømmerne, saa er Betalingen af den aarlige faste Afgift, som og Resten af Købesummen med Renter at erlægge i den i Hertugdømmerne gangbare Mønt, og beregne efter Courant.

Jeg har udstedt denne Købe- og Overladelseskontrakt under Afkald paa alle tænkelige Exeptioner og Udflugter, saavel i det almindelige som i det særlige, egenhændigt underskrevet og med mit eget Segl beseglet.

Saaledes skeet d. 1. Maj 1788.

Conrad Reventlow.

Denne Kontrakt er skreven paa tysk. Retssproget var Tysk dengang her. Derimod er de vedhæitede Konditioner skrevet paa Dansk, saa Folk kunde forstaa dem. Der er i disse Konditioner 15 Paragraffer. Af dem hidsættes:

\$ 1. Forbemeldte Bolsmand i Sottrup, Snogbak og Dybbel, som aldeles ingen Ejendomsrettighed har til deres iboende Bole, overlades samme, med dertil hørende Landerier og Skovparter, som samme, efter Landmaalingen og Udskiftningen, paa nærværende Tid, sig befinder, tilligemed det Herskabelige Beslag og Bygninger, til fuldkommen Arv og Eje.

\$ 3. Med Kirke- og Skolesager bliver det paa den gamle Fod. Kjøbere skal betale efter Mark Guld til de forefaldende Criminal, Physikat og Politi-Bekostninger som ogsaa ved Fangernes Bevogtning og Staadderkongens Underholdning.

§ 4. Jagten forbeholder Herskabet sig.

\$5. Kjøbere skal ligesom før, lade maale deres Brødkorn og Malt paa Sandbjerg Mølle. Men fra alle andre Mølletjenester som Mølledæmnings og Slusens Reparation skal de aldeles være befriet. Det forbliver til evig Tid ved den hidtil sædvanlige Matte som er den 20de Skjappe af Kornet som maales. 
\$ 9. For at skaffe Kobere Credit skal der oprettes en Skyld- og Panteprotokol.

$\S$ 10. Alle Hoveritjenester, som Kjøbere hidtil har gjort, saavel til Pagtgaarden, som til Herskabet, og ellers har leveret til Gaarden hører op fra 1. Maj 1788 aldeles, men til den Tid præsteres de endnu fuldkommen o. s. v.

Jørgen Christensen Mattesens Gaard, der nu horer til Nørremølle, var 60 Tdr. Land meget god Jord. Ved Købebrevets Udstedelse betalte han 200 Rdl. og udstedte en Obligation paa $900 \mathrm{Kr}$. der blev indført i den ny Protokol.

1789 brændte Gaarden, den blev flyttet ud af Byen og opbygget igen 1790. 30. April 1792 kunde han afbetale $100 \mathrm{Rdl}$. til Rest altsaa $800 \mathrm{Rdl}$., den 12. Juni 1794 afbetalte han 200 Rdl. til Rest altsaa 600 Rdl. 1795 afbetalte han $200 \mathrm{Rdl}$, Rest 400, 1796 afbetalte han 200 Rdl., Rest 200 og 15. November 1797 betalte han Resten af Kobesummen.

Jørgen Christensen Mattesen udbetalte altsaa hele Gaarden i 91/2 Aar, samtidig med at Gaarden nu var udflyttet og nyopbygget.

1797 udparcellerede Greve Conrad Hovedgaarden, saa der nu kun er knap $100 \mathrm{Td}$. Agerland og $150 \mathrm{Td}$. Skov. Den udparcelleredes i 14 Parceller. 1. Parcel var Pagtgaarden (den oprindelige Hovedgaard). 2. var Ravnskobbel (skrives Rauenskoppel) 13. Parcel var Nørremølle, der var kun $4^{1 / 2}$ Td. Land til, bestaaende af den oprindelige Mølledam nu Eng og en lille Lykke Agerland i Snogbæk. Den blev solgt til Grevens Gartner Christjan Asmussen ude $\mathbf{n} \mathbf{K} ø \mathbf{b}$ eskilling.

Af denne Kontrakt hidsættes:

Jeg Conrad Georg, Greve til Reventlow hans kong. Majestæts Kanmerherre og Kommandeur i Søetaten, erklærer herved for mig og mine Lens- 
efterfølgere, at jeg ved Nedlæggelsen af Godset Sandbjerg har overladt den 13de Parcel, Nørre Mølle, bestaaende af den Snogbækker Lykke ca. 4 Tønder Ager og England, til min Gartner Christjan Asmussen uden Købeskilling til et Familiested mod en, af samme til Godsherskabet paa Sandbjerg, at erlægge aarlig Canon af $13 \mathrm{Rdl}$. $16 \mathrm{Sk}$., der svares promte hvert Aar til Jul. Ligesom nu han og hans Arvinger iøvrigt er skyldige at overholde de $i$ de vedhæftede Conditioner særlige Prostanda, ligesom de andre Sandbjerger Parcellister, saa skal han, og de andre ogsaa kunne glæde sig ved de i Conditionerne nævnte Friheder og Rettigheder. Saaledes skal Asmussen, saalænge han er $\mathrm{i}$ min Tjeneste, være fri for at betale den aarlige Afgift. Endvidere skal det være Christjan Asmussen tilladt at indrette et Brændevinsbrænderi og en Grynmølle, paa hvilken sidste han dog ikke maa maale Meel eller Korn, men kun Gryn.

skulde endelig den Sandbjerger Vandmølle blive nedlagt og en Kornvejrmølle anlagt istedet, saa skal Christjan Asmussen, i Fald jeg og han da lever, have Lov til at bygge en Vejrmølle til hvilken samtlige grevelige Undersaatter i Sottrup og Snogbæk som ogsaa de til Sottrup hørende Parcellister skal være tvangspligtig til at lade deres Brødkorn og Malt maale. Dog skal han være pligtig til at maale det herskabelige Korn uden Matte, følgelig ganske uden Betaling.

Til Bekræftelse har jeg egenhændig underskrevet og beseglet denne Contrakt.

Saaledes skeet Sandbjerg d. 14. April 1797.

Conrad Reventlow.

Christjan Asmussen gik det imidlertid ikke saa godt. Han fik nok en lille Grynmolle til Haandkraft, jeg har som Dreng leget med Hjulene af denne Mølle, men Brænderi og Vejrmølle kom ikke. Den skiftede Ejer flere Gange, indtil min Farfar kjøbte den 1819. Da kom Brændevinsbrænderiet i Gang. Lige før Krigen brændte Sandbjerg Vandmølle, den er ikke bygget op igjen, og Vandet gaar nu den naturlige $\underset{19}{V e j}$ 
gjennem Nørremølle. Den af Hertug Hans d. yngre med stort Hoveriarbejde og Besvær gravede Kanal ligger nu tør. Dæmningen, han satte, tjener nu blot som Vej. Men Vejrmølle blev ikke bygget.

Det vil af disse gamle Kontrakter ses, at Grev Conrad var Bønderne og sine Undergivne en god Mand. Tænkeligt er det, at han er bleven stærkt paavirket af sin yngre Broder Christjan Ditlev Frederik.

Grev Conrad var Sømand, men han var dog ogsaa saa meget Landmand, at han allerede den Gang tænkte at gjennemgrave Dæmningen ved Sandbjerg, nedlægge Vandmøllen og derved lægge hele Nydamlavningen tør.

Som allerede anfort blev det overordentlig daarlige Tider efter Grev Conrads Død. Han døde ugift og uden Arvinger. Lensgrevskabet Reventlow-Sandbjerg gik da over til den yngre Broder Christjan Ditlev Frederik.

Tiderne var nu saa slette at Bønderne ikke kunde betale Skatterne, der dog visselig var smaa, sammenlignet med Nutiden, af en Gaard til Værdi ca. 100,000 Kr. $40 \mathrm{Rdl}$. Courant nemlig $28 \mathrm{Rdl}$. Contribution og 12 Rdl. Canon foruden Kopskat. 1822 indgav samtlige Grevens Bønder et Andragende til deres daværende Greve Christjan Ditlev Frederik Reventlow paa Christianssæde paa Lolland om at faa Henstand og Lettelse med Skatterne.

Derpaa kom følgende Svar dateret 16. Januar 1823:

"Eders Brev, kjære Bønder af 28.de forrige Maaned, som jeg idag har modtaget, har jeg læst med megen Deltagelse og med det Ønske, med Raad og 
Daad at kunne bidrage til at lette Eders Bekymringer.

Vi har havt den Lykke, i flere Aarhundreder at have havt Konger der elskede Deres Undersaatter, men ingen af dem, har virket saa meget til Bondestandens Bedste, som vor gode nuværende Konge. Fra det Øjeblik at han naaede den Alder, at han kunde være sin Faders Raadgiver, og da, i hans Sindssvaghed, bestyrede alle Rigets Anliggender, men som en god Søn lod Faderen beholde AEren for Alt det gode der skete efter hans Raad.

Den i Danmark under haarde Kaar sukkende Bondestand skaffede han Beskærmelse mod Undertrykkelse og Frihed for Fødestavnsbaandet, der bandt enhver i samme til det Gods, i hvilket han var bleven født, samt Bestemmelser i Hoveriets Ydelser, for hvilke der næsten ingen Grænser havde været satte. Alt hvad der kunde bidrage til Agerdyrkningens Fremme blev ved vise Lovgivninger befordret og Hindringer ryddede af Vejen ikke alene i Danmark men ogsaa i Hertugdømmerne. Min Farfaders, min Faders og min Broders milde Tænkemaade havde allerede udslettet Tanken om Livegenskab paa Grevskabet Reventlow, der i begge Hertugdømmer fandt Sted hos de fleste adelige Godsejere, som gerne vilde byde meget for at hindre hans, Kongens landsfaderlige Hensigts Opnaaelse, og under vor nuværende Konges vise Bestræbelser voxede saaledes $i$ en lang Række af Aar Undersaatternes Velstand, medens alle andre Lande ødelagdes under Krigens Voldsomheder. Ingen kunde finde grundet Aarsag til at klage over Skatternes Byrde. Det faar vi at takke hans gode Hjerte, hans Klogskab og fredelige Sindelag.

Men midt i Freden, under de venskabeligste Forsikringer, og uden mindste rimeligt Paaskud angreb England Danmark, og ødelagde med en mægtig Armé og Flaade en stor Del af Hovedstaden, bortførte den aftaklede skønne Flaade, der vilde have kostet dem blodige Hoveder, om de havde villet, ikke bortrøve, men borttage den i aaben Fejde paa Søen, borttog Danmarks fleste Handelsskibe og ødelagde Danmarks og Hertugdømmernes blomstrende Handel. 
- - Nu rakte Skatterne ikke mere til, til at bestride Kongens Udgifter, nu saa megen Ulykke rammede hans Riger og Lande. Skatter maatte han med blødende Hjerte underskrive, og da de dog ikke kunde tilstrække, maatte han betale med Bancosedler. som han ikke nu under Krigen kunde udrede $i$ Penge, og disses Værdi, nedsank derfor til næsten intet.

- - Nu er vel denne ulykkelige Tidspunkt overstaaet, og Freden er vendt tilbage. Men Saarene, som Krigen har slaget, er ikke lægte. Nogen Gjæld har Kongen maattet gjøre, af hvilken Renterne maa svares, og noget maa afbetales paa Hovedsummen. Mange Betjente og Officerer, som under Krigen maatte antages, maa nu pensioneres, og da Handelen er betydelig meget mindre end før Krigen, saa er ogsaa Toldindtægterne, der omtrent udgjorde den halve Kongens Indtægt, meget formindsket. Kongen gjør hvad muligt er for at spare paa Udgifterne for at kunne lette sine kjære Undersaatter Skatterne, der trykker dem alle. Ogsaa har han allerede i dette Aar med Plakat af 10de d. M. forlænget Henstanden med de tilbagestaaende Bankrenter for Aarene 1813 til 1818. Men selv denne Lettelse, som han har paatænkt og vil paatænke, kan ikke afhjælpe Landmandens trange Kaar saa længe Kornpriserne bliver saa lave, som de nu ere; thi ingen Mand har den halve Indtægt af sin Gaard af Korn og Fedevarer, som han har havt i de sidste Halvhundrede Aar, til de sædvanlige Middelpriser. $O g$ den Mand, der ejer sin Gaard med Gjæld, der ikke svarer til Jordejendommens Værdi, er ilde faren, thi denne er nu nedsjunken til det halve, eller en ringe Deel. Den Mand der har skiftet mellem sine Frænder, hvis Arvelodder er bleven staaende uopsagt $i$ Gaarden, og ingen anden Gjæld har, han nødes nu ofte, naar disse Arvelodder ham opsiges at opgive sit Bo, og fattig og tomhændet at forlade sin arvede Gaard, uden mindste hans Brøde. - Denne haarde Skjæbne har Agerdyrkerne i disse Lande ikke alene men i alle bekjendte Lande. Thi efter Kornmanglen, under hvilken mange Lande har sukket en Del Aar, og i disse, mange Mennesker er døde af Sult og Elendighed, har Gud nu alminde-- 
ligen velsignet deres Agre med en rig Høst og alle har havt Overflødighed af Korn. - Vi lider meget ved de lave Kornpriser, men hine have lidt langt mere ved Mangelen af Korn, under hvilken mange for ikke at sulte ihjel maatte udvandre fra deres Fødeland, og mange sultede dog ihjel, i visse Egne af Schweiz omtrent en Sjettedel af Folkemængden, endskjønt de Velhavende er meget velgjørende og alle mulige Foranstaltninger gjordes til Korns Indkjob. Hos os sulter ingen ihjel, endskjønt vores Velstand forringes. Men Hungersnøden i andre Lande er nu ophørt, ligesom Kornpriserne efter Sandsynlighed igjen, naar Skibsfarten begynder, vil rejse sig lidt, og efterhaanden de gamle Middelpriser vil kunne opnaas. Thi Høsten har ikke almindeligen været god, de store Oplag i Handelsstæderne ere betydeligen formindskede, og af Sommerkorn især er udenlands ingen Overflødighed. Jeg har oplevet ligesaa ringe Priser i Aarene $1776^{\circ}$ og 77, og i Aaret 1775 solgte jeg min Hvede for $4 \mathrm{R}$. (4 curant) og i 1776 og 77 var Prisen for Hvede $1^{2 / 3}$ R., for Byg $1 \mathrm{R}$. $84 \mathrm{og}$ for Havre $40 \mathrm{Sk}$. lybsk. I Aaret 1778 rejste Priserne sig igjen til det de plejede at være. Vel vare Skattene ikke saa store som nu, men Agerdyrkningen er siden den Tid fremskreden, og eders Gaarde frembringer nu langt mere Korn, Kreaturer og Fedevarer end dengang. Hvad der er skeet vil igjen skee og vi vil snart see bedre Tider. Den nuværende Tid skal opmuntre til den muligste Sparsomhed og til at anstrenge al vor Flid til fortsatte Forbedringer, at vi fremdeles maa see endnu større Frugtbarhed af Jorden. Meget er udrettet, men meget mere staar endnu tilbage for fornuftige og flittige Agerdyrkere, for hvilke jeg anseer Eder.

Min salig Broder overlod Eder eders Gaarde i fri Ejendom efter mit og min yngre Broders Raad og Samtykke imod en billig Afgift i Forhold til deres Værdi, og for en langt ringere end Bønder i lige Tilfuclle senere har maattet betale deres Godsejere, men hans og vores Hensigt var, at Bønderne med Herskabet, skulde nyde og dele Fordelene af Jordens bedre Benyttelse ved Hjælp af Udskiftningen og de Forbedringer som Ejendomsrettighederne maatte opmuntre dem til at gøre. - - 
Om jeg ikke havde været nødsaget til at paadrage mig en meget betydelig Gjæld for at forbedre mine herværende Bønders Kaar, og om jeg ikke til mine mange Børns og Børnebørns Underhold havde store Udgifter, vilde jeg gjerne til mange gjøre Forskud paa Skatter og give Delation paa Afgifter til mig, der falder jer meget trykkende, men min Evne er desværre nu ikkun ringe og saadan, at jeg ikke kan undvære noget betydeligt Afskjær i mine Indtægter, der i Danmark ligesom Eders bestemmes efter Kornpriserne, og er ned sjunken til det halve af det, de $i$ sædvanlige Aar ere. I maa derfor af yderste Kræfter søge at udrede, hvad der 'paalægges Eder, og hvem der gjør det, og endnu staar til at redde, den vil jeg, saa vidt min Evne tilstrækker, bringe mig efter, hvorved jeg dog maa gjentage, at min Evne i denne Tid kun er liden, og ingen af Eder kan derfor gjøre sikker Regning paa af mig at nyde Skaansel ved Betaling af Skatter og Afgifter.

- - Vi har hidtil kun gjort liden personlig $\mathrm{Be}$ kjendtskab med hinanden, men jeg vil søge, om Gud vil, at blive noget længere paa Sandbjerg, for nøje hos Eder at underrette mig om Eders Kaar, og som jeg altid har gjort at være mine gode Bønder til Nytte med Gode Raad. - - Om jeg, som jeg haaber i Sommer kommer til Sandbjerg, og igjen tager tilbage, ønskede jeg at nogle af Eder kunde finde Lejlighed til at besøge mig her, paa det I kunde se mine Bønders Tilstand, og de kunde lære Eder og I af dem, til heldigere at gaa frem i Forbedringer.

- - Jeg ønsker hjerteligt at Gud endnu i min høje Alder vil lade mig opleve den Glæde, at kunne gjøre vel mod Eder, og at jeg endnu maa see Eders Velstand igjen at forøges og Eder selv glade over den Velsignelse Gud skjænker Eder.

Jeg har nu til Eder aabnet mit Hjerte, som en Fader aabne det til sine gode Børn, og befaler Eder Gud, uden hvis Velsignelse vi Intet formaar.

Pederstrup, d. 16de Januar 1823.

$$
\text { C. D. F. Reve } n t l o w \text {. }
$$

Til mine kjære Bønder paa Sandbjerg, Ballegaard og Beuskov Godser. 
I Dybbøl Sogns Kirkebog staar under 20. April 1815, at Conrad Georg Lehnsgreve til Sandbjerg m. m. var født 1749 og død 1815. Fader ....... mere staar der ikke, men der er ladt en Side Plads til nærmere Redegjørelse for hvem han var, den er imidlertid aldrig bleven udfyldt, maaske fordi han og Præsten vel ikke stod paa den bedste Fod overfor hinanden. Grev Conrad oplevede at se Bøndernes vældige Opsving efter Stavnsbaandets Løsning, Udskiftningen, Fællesskabets Ophævelse og Bøndergaardenes Salg til fri Ejendom. Han oplevede ogsaa at se Englænderne tage den "skjønne aftaklede Flaade«, som Commandeur i Flaaden, og den store Nedgang og Fattigdom, der fulgte efter den store Krig.

Men hans Minde skal bevares og leve her, for hall var Bondens Ven og Velgjører. 